Article

\title{
Finite Element Analysis of Aluminum Honeycombs Subjected to Dynamic Indentation and Compression Loads
}

\author{
A.S.M. Ayman Ashab, Dong Ruan*, Guoxing Lu and Arafat A. Bhuiyan \\ Faculty of Science, Engineering and Technology, Swinburne University of Technology, Hawthorn, VIC 3122, \\ Australia; aashab@swin.edu.au (A.S.M.A.A.); glu@swin.edu.au (G.L.); abhuiyan@swin.edu.au (A.A.B.) \\ * Correspondence: druan@swin.edu.au; Tel.: +61-03-9214-8258
}

Academic Editor: Xiaodong Huang

Received: 27 January 2016; Accepted: 29 February 2016; Published: 4 March 2016

\begin{abstract}
The mechanical behavior of aluminum hexagonal honeycombs subjected to out-of-plane dynamic indentation and compression loads has been investigated numerically using ANSYS/ LS-DYNA in this paper. The finite element (FE) models have been verified by previous experimental results in terms of deformation pattern, stress-strain curve, and energy dissipation. The verified FE models have then been used in comprehensive numerical analysis of different aluminum honeycombs. Plateau stress, $\sigma_{p l}$, and dissipated energy ( $E_{I}$ for indentation and $E_{C}$ for compression) have been calculated at different strain rates ranging from $10^{2}$ to $10^{4} \mathrm{~s}^{-1}$. The effects of strain rate and $t / l$ ratio on the plateau stress, dissipated energy, and tearing energy have been discussed. An empirical formula is proposed to describe the relationship between the tearing energy per unit fracture area, relative density, and strain rate for honeycombs. Moreover, it has been found that a generic formula can be used to describe the relationship between tearing energy per unit fracture area and relative density for both aluminum honeycombs and foams.
\end{abstract}

Keywords: finite element analysis; indentation; relative density; tearing energy; strain rate

\section{Introduction}

Over the last few decades, man-made honeycombs have been widely used in many industries due to their properties such as high strength to weight ratio and good energy absorption capabilities. Honeycombs are manufactured from materials such as aluminum, nomex, polymer, and ceramic. Aluminum honeycombs can be used as industrial products as well as core materials in sandwich panels in various fields of engineering such as aerospace, aircraft, automotive, and naval engineering [1,2].

A number of studies have been conducted on the out-of-plane compression of aluminum honeycombs at low and intermediate strain rates [3-8]. Zhou and Mayer [3], Wu and Jiang [4] and Baker et al. [5] conducted compression tests on aluminum honeycombs at different strain rates in the out-of-plane direction and found that the plateau stress, $\sigma_{p l}$, increased with strain rate, $\dot{\varepsilon}$. Both Xu et al. [6] and Ashab et al. [7] found that with the increase of $t / l$ ratio (cell wall thickness to edge length ratio) and strain rate, plateau stress, $\sigma_{p l}$, increased. Vijayasimha Reddy et al. [8] concluded that energy absorption capacity of aluminum honeycombs increased with the impact velocity under out-of-plane compression load. Alavi and Sadeghi [9] conducted experiments on foam-filled aluminum hexagonal honeycombs under the out-of-plane compression loads. They observed that the crushing strength of bare honeycombs and foam-filled honeycombs increased with strain rate and bare honeycombs were more sensitive to strain rate than foam-filled honeycombs. Mozafari et al. [10] employed ABAQUS software and observed that the mean crushing strength and energy absorption of foam-filled honeycomb were greater than the sum of those of bare honeycomb and foam. 
Along with the experimental investigation, finite element analysis (FEA) has also been conducted by various researchers [11-14] to study the mechanical behavior of aluminum honeycombs. Guo and Gibson [11] conducted numerical analysis of intact and damaged honeycomb properties in the in-plane direction and reported that modulus and strength decreased due to the effect of single and isolated defects of various sizes. They also investigated the separation distance between two defects and its effect on the plastic collapse strength and Young's modulus. Ruan et al. [12] employed ABAQUS to investigate the effects of $t / l$ ratio and impact velocity on the in-plane deformation mode and plateau stress. They derived an empirical formula to describe the relationship between the plateau stress, $t / l$ ratio and velocity. Hu et al. $[13,14]$ conducted experiments as well as finite element analysis to study in-plane crushing of aluminum honeycombs. They proposed a dynamic sensitivity index to describe crushing strength and energy absorption.

Deqiang et al. [15] used ANSYS/LS-DYNA [16] to study the out-of-plane dynamic properties of aluminum hexagonal honeycomb cores in compression. They found that the out-of-plane dynamic plateau stresses of honeycombs were related to the impact velocity, $t / l$ ratio, and expanding angle $\theta$ of honeycombs by power laws. Yamashita and Gotoh [17] conducted both experimental and numerical analyses on the compression of aluminum honeycombs. The crushing strength was related to the $t / l$ ratio of honeycombs by a power law with the exponent of $5 / 3$, which was the same as the theoretical equation derived by Wierzbicki [18]. The computer simulation carried out by $\mathrm{Xu}$ et al. [19] also found a power law relationship between the out-of-plane compressive strength of aluminum honeycombs and the strain rate and $t / l$ ratio.

A limited number of experiments were conducted on aluminum honeycombs subjected to indentation [3,7] at very low and intermediate strain rates. Zhou and Mayer [3] conducted quasi-static indentation tests on aluminum honeycombs to study the influence of specimen size on the force versus displacement curve. They found flatter and lower indentation force for the larger specimen. This was because larger specimens had a larger amount of surrounding cells, which provided stiffer support and resulted in fewer cells to be involved in tearing. The four primary deformation mechanisms were shear, tearing initiation, tearing, and compression. Zhou and Mayer also used different indenters, such as square, rectangular, and circular, to study the effect of indenter shape. Ashab et al. [7] conducted indentation tests on three types of aluminum honeycombs at strain rates from 10 to $10^{2} \mathrm{~s}^{-1}$ and found that the tearing energy increased with the $t / l$ ratio of honeycomb and strain rate. However, due to the limited honeycombs and testing machines available, previous studies were not able to draw quantitative conclusions on the effects of $t / l$ ratio and strain rate on the tearing energy of honeycombs.

In the present paper, numerical simulation is performed using ANSYS/LS-DYNA [16] to study the dynamic out-of-plane properties of aluminum hexagonal honeycombs with various $t / l$ ratios subjected to indentation. Compression of honeycombs is also simulated in order to calculate the tearing energy in indentation. Full-scale FE models of honeycombs are verified by the previous experimental results. The verified FE models are then used to investigate the effects of $t / l$ ratio and strain rate on the plateau stress and tearing energy of honeycombs subjected to indentation. Empirical equations are proposed.

\section{Finite Element (FE) Modeling}

In the present paper, numerical analysis of aluminum honeycombs was carried out using ANSYS/LS-DYNA [16]. Two types of honeycombs, differing in cell size and cell wall thickness, were simulated. The honeycombs are named as H31 and H42 for honeycombs 3.1-3/16-5052-.001N, $4.2-3 / 8-5052-.003 \mathrm{~N}$, respectively. The specifications of the honeycombs, provided by the manufacturer, are listed in Table 1 . The dimensions of each honeycomb model are the same as those of the actual specimen used in the previous experiments [7]. The height of all honeycombs, $h$, was $50 \mathrm{~mm}$. The in-plane dimensions of all honeycomb specimens were $180 \mathrm{~mm} \times 180 \mathrm{~mm}$ in indentation simulation (Figure 1a) and $90 \mathrm{~mm} \times 90 \mathrm{~mm}$ in compression simulation (Figure 1b). 
Table 1. Specification of aluminum honeycombs [20].

\begin{tabular}{ccccc}
\hline Type & $\begin{array}{c}\text { Material } \\
\text { Description }\end{array}$ & $\begin{array}{c}\text { Cell Size, } \mathbf{D} \\
(\mathbf{m m})\end{array}$ & $\begin{array}{c}\text { Single Cell Wall } \\
\text { Thickness, } \mathbf{t}(\mathbf{m m})\end{array}$ & $\begin{array}{c}\text { Cell Wall Thickness to } \\
\text { Edge Length Ratio, } \mathbf{t} / \mathbf{1}\end{array}$ \\
\hline H31 & $3.1-3 / 16-5052-0.001 \mathrm{~N}$ & 4.763 & 0.0254 & 0.00924 \\
H42 & $4.2-3 / 8-5052-0.003 \mathrm{~N}$ & 9.525 & 0.0762 & 0.0139 \\
\hline
\end{tabular}

* In the material description, 3.1 and 4.2 are the nominal densities in pounds per cubic foot, 3/16 and 3/8 are the cell size in inches, 5052 is the aluminum alloy grade, 0.001 or 0.003 is the nominal foil thickness in inches, and $\mathrm{N}$ denotes non-perforated cell walls. Data were provided by the manufacturer, HEXCEL ${ }^{\circledR}$ (Stamford, CT, USA). The relation between cell size, $D$ end cell edge length, $l$ is: $D=\sqrt{ } 3 l$.

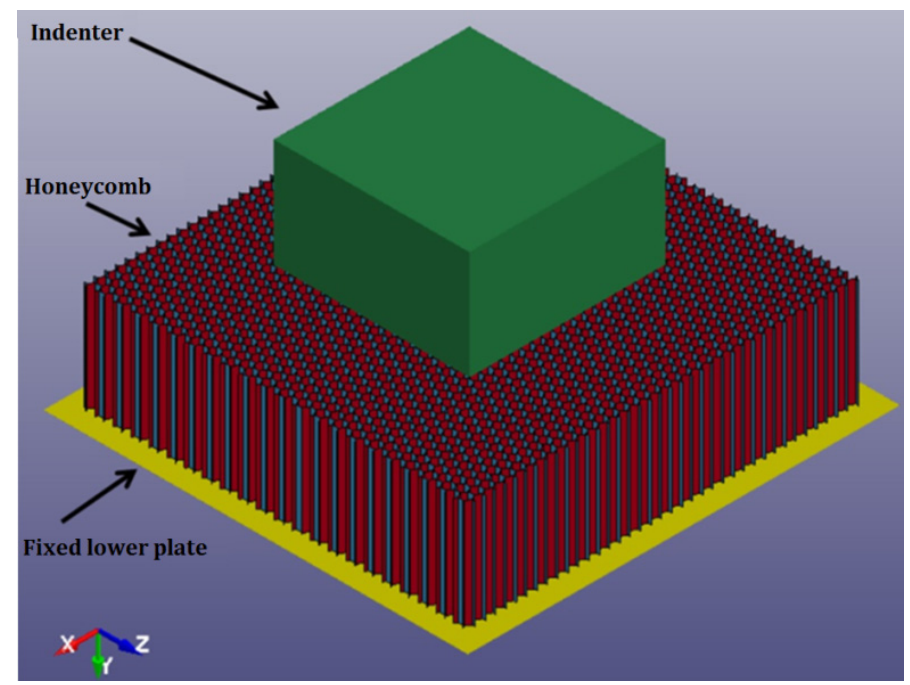

(a)

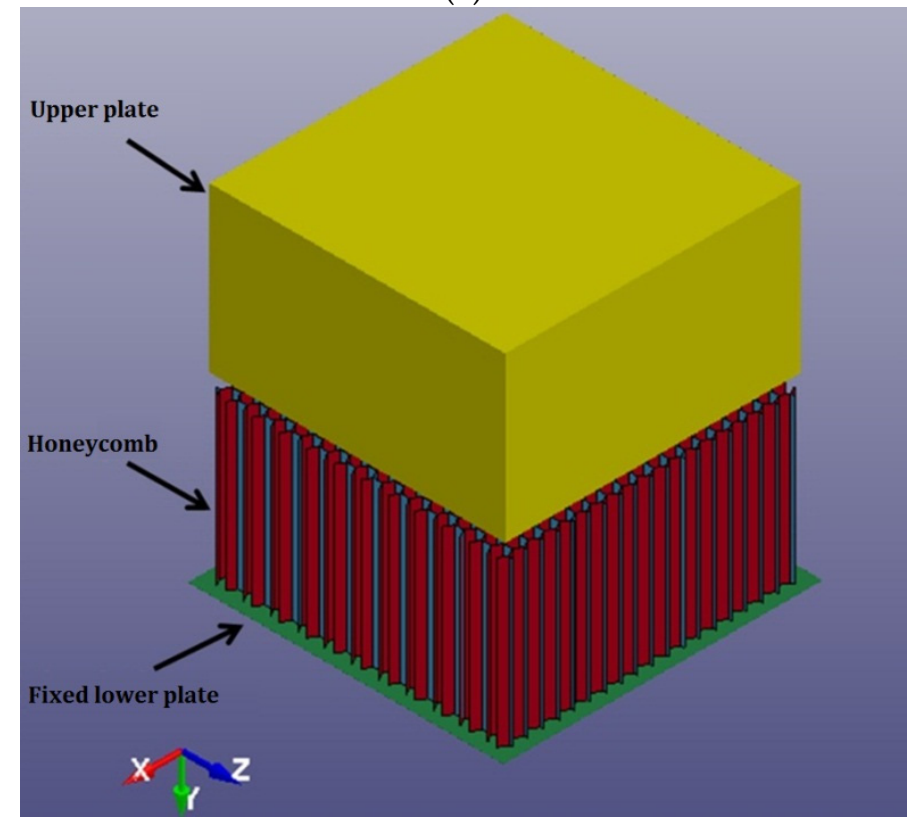

(b)

Figure 1. Typical FE models of honeycomb H31: (a) indentation; (b) compression.

Aluminum honeycomb walls were simulated using a bilinear kinematic hardening material model. The corresponding material properties are listed in Table 2. Belytschko-Tsay Shell 163 elements with five integration points were employed to simulate the honeycomb cell walls for high computational efficiency [19]. In each honeycomb cell, single wall thickness was employed for the four oblique walls 
and double wall thickness was employed for the two vertical walls. To identify the optimum element size, a convergence test was carried out. Five different element sizes-2.1 mm, $1.4 \mathrm{~mm}, 0.7 \mathrm{~mm}, 0.3 \mathrm{~mm}$, and $0.15 \mathrm{~mm}$-were used to simulate compression of honeycombs at $5 \mathrm{~ms}^{-1}$. No significant difference (less than 7\%) was observed between the results for element sizes $0.7 \mathrm{~mm}$ and $0.15 \mathrm{~mm}$. Therefore, in this FE analysis of aluminum honeycombs an element size of $0.7 \mathrm{~mm}$ was employed. Since tearing of cell walls happened in honeycombs under indentation, MAT_ADD_EROSION failure criterion with a maximum effective strain of 0.3 [21] was used in the indentation models. All degrees of freedom of one node at a corner of the honeycomb were fixed to keep the honeycomb in place (i.e., no rigid body movement).

Table 2. Material properties used in the FE model of aluminum honeycombs [19].

\begin{tabular}{cccccc}
\hline $\begin{array}{c}\text { Material } \\
\text { Properties }\end{array}$ & $\begin{array}{c}\text { Mass } \\
\text { Density }(\rho)\end{array}$ & $\begin{array}{c}\text { Young's } \\
\text { Modulus (E) }\end{array}$ & $\begin{array}{c}\text { Poisson's } \\
\text { Ratio }(v)\end{array}$ & $\begin{array}{c}\text { Yield Stress } \\
\left(\sigma_{\text {ys }}\right)\end{array}$ & $\begin{array}{c}\text { Tangent } \\
\text { Modulus (E }\end{array}$ \\
\hline Magnitude & $2680 \mathrm{~kg} / \mathrm{m}^{3}$ & $69 \mathrm{GPa}$ & 0.33 & $292 \mathrm{MPa}$ & $690 \mathrm{MPa}$ \\
\hline
\end{tabular}

In physical experiments, honeycomb specimens were placed on a fixed lower plate and crushed by an upper plate (in compression) or indenter (in indentation). In FE models, the lower plate was simulated by a rigid plate while the upper plate and indenter were simulated by rigid bodies. The lower plate was $1 \mathrm{~mm}$ (thickness) $\times 200 \mathrm{~mm} \times 200 \mathrm{~mm}$. The upper plate and indenter were cuboids with dimensions of $50 \mathrm{~mm}$ (height) $\times 90 \mathrm{~mm} \times 90 \mathrm{~mm}$, the same as in the previous experimental study [7]. The material properties used for the plates and indenter are listed in Table 3.

Table 3. Material properties used in the FE model of rigid plate and bodies [19].

\begin{tabular}{cccc}
\hline Material Properties & Mass Density $(\rho)$ & Young's Modulus (E) & Poisson's Ratio (v) \\
\hline Magnitude & $7830 \mathrm{~kg} / \mathrm{m}^{3}$ & $207 \mathrm{GPa}$ & 0.34 \\
\hline
\end{tabular}

For the lower plate, all degrees of freedom were fixed. For the upper plate (in compression) and indenter (in indentation), all three rotational movements and two transitional movements in the $X$ and $\mathrm{Z}$ directions were fixed. The upper plate or indenter could move in the negative $\mathrm{Y}$ direction at a constant velocity to compress or indent honeycombs.

A tiny gap $(0.1 \mathrm{~mm})$ between the fixed lower plate and the honeycomb was employed to avoid the initial penetration at the beginning of the simulation. For the same reason, an initial gap of $5 \mathrm{~mm}$ was also introduced between the upper plate or the indenter and the honeycomb. SURFACE_TO_SURFACE contacts were employed between the plates or indenter and honeycomb. Typical finite element models of indentation and compression of honeycombs in the out-of-plane direction are shown in Figure 1.

\section{Validation of FE Models}

\subsection{Deformation Patterns}

Figure 2 shows comparison between the experimental and simulated deformation of honeycomb $\mathrm{H} 31$ in compression at $5 \mathrm{~ms}^{-1}$. Identical deformation mode in both the experiments [6,7] and FEA was observed: when the honeycomb was compressed in the out-of-plane (T) direction, buckling of cell walls was initiated from both the top and bottom ends and propagated to the middle of the honeycomb (Figure 2a,b). Figure 2c,d show the deformed honeycomb H31 after crushing in the experiment and FEA, respectively. Almost identical deformation patterns were found in the experimental and FEA results. Due to the stronger lateral constraints in the central part of the honeycomb, the honeycomb deformed in a much more regular pattern in the central part. However, along the four edges of the indenter, honeycomb cell walls deformed in an irregular pattern. Similar deformation patterns were observed for honeycomb H42 in compression. 


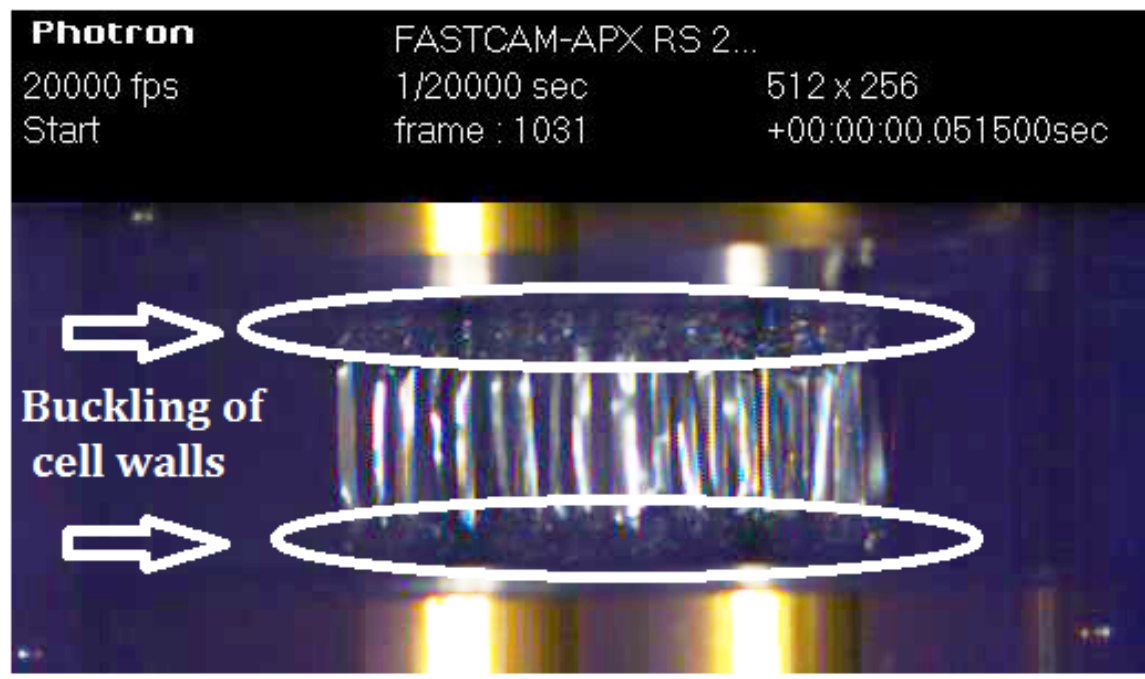

\section{Experimental compression}

(a)

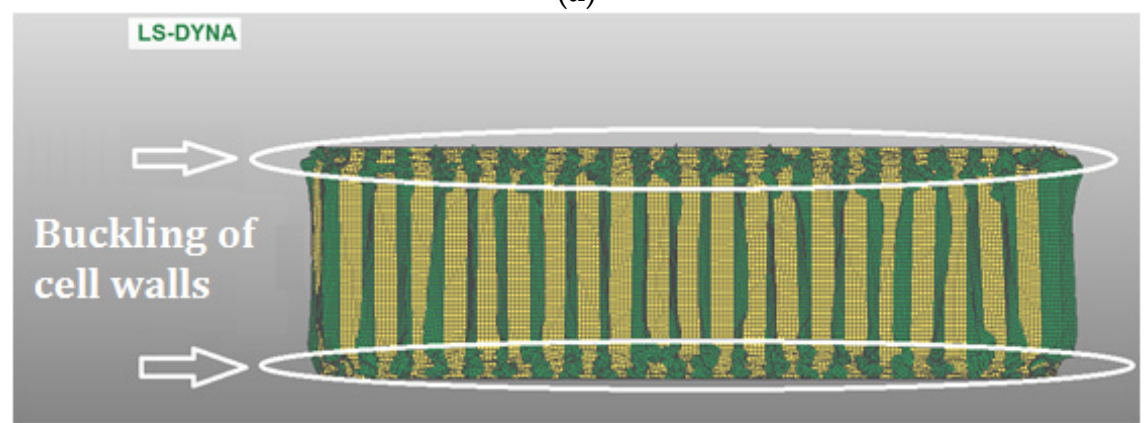

FEA compression

(b)

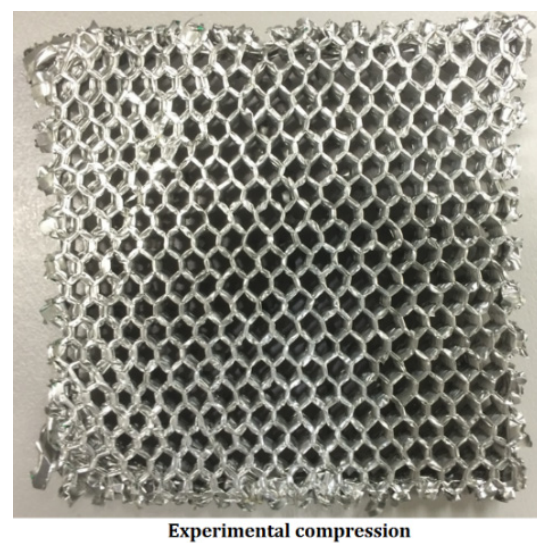

(c)

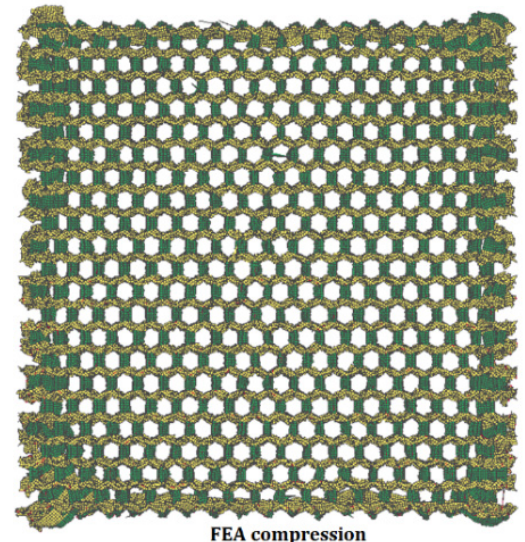

(d)

Figure 2. Comparison between experimental and simulated deformation mode of honeycomb H31 under compression: (a) experimental result; (b) FEA result; (c) experimental post-test specimen; (d) FEA post-test specimen.

Figure 3 shows a comparison between experimental and FEA deformation patterns of honeycomb H42 subjected to out-of-plane indentation at a velocity of $5 \mathrm{~ms}^{-1}$. Similar irregular tearing patterns were observed in both the experiment and FEA. The FEA results of another type of honeycomb, H31, also showed a similar deformation pattern to that observed in the previous experiments [7]. 


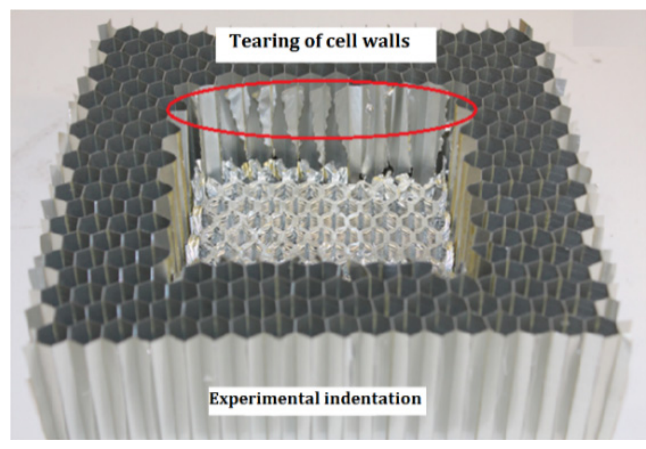

(a)

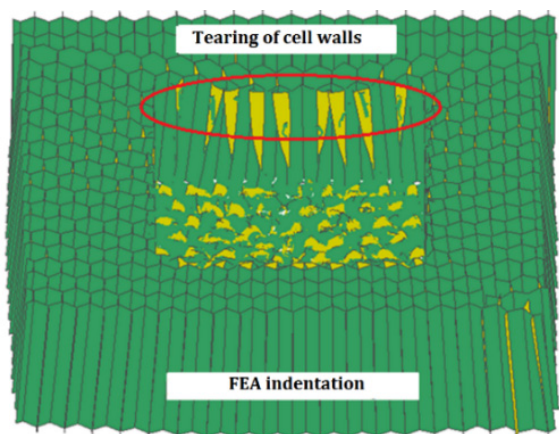

(b)

Figure 3. Comparison between experimental [7] and FEA deformation pattern of honeycomb H42 under indentation: (a) experimental post-test specimen; (b) FEA post-test specimen.

\subsection{Stress-Strain Curves}

FEA and experimental stress-strain curves of two types of honeycombs are shown in Figure 4. Similar general trends in the stress-strain curves were found for both honeycombs in indentation and compression.

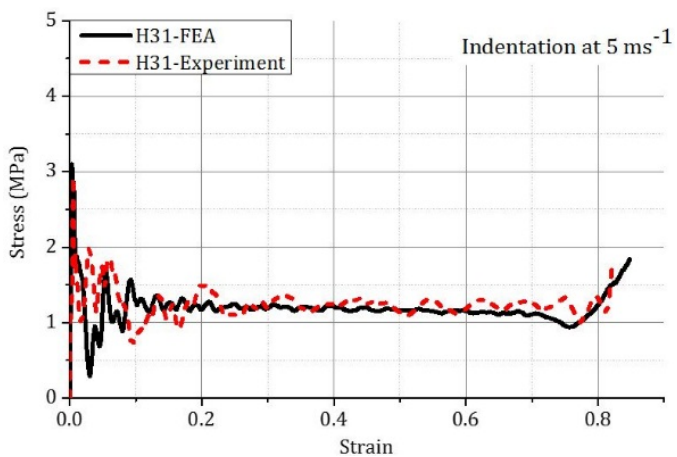

(a)

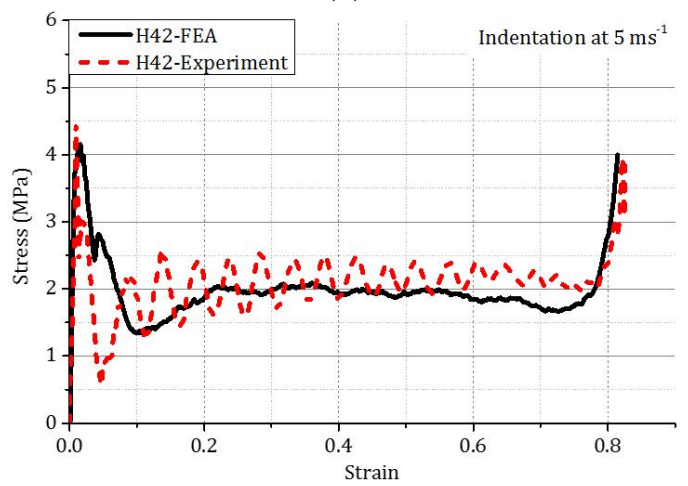

(c)

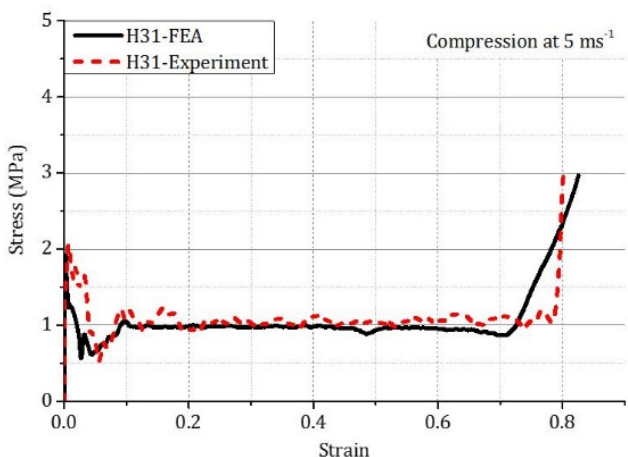

(b)

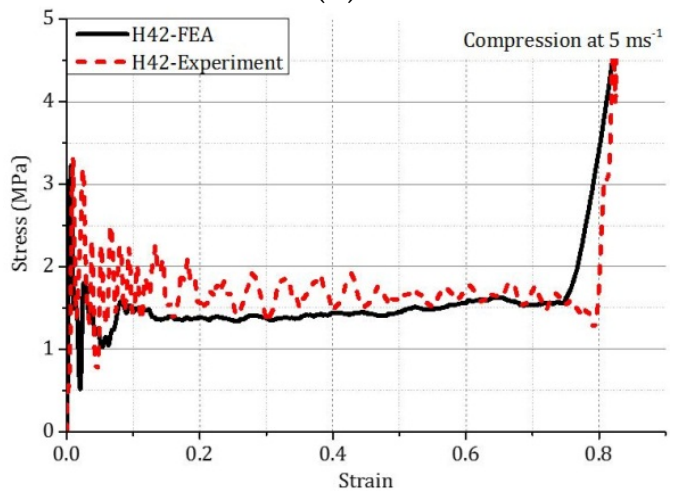

(d)

Figure 4. Experimental and FEA stress-strain curves of two types of honeycombs at $5 \mathrm{~ms}^{-1}$ : (a) indentation of $\mathrm{H} 31$; (b) compression of $\mathrm{H} 31$; (c) indentation of H42; (d) compression of H42.

The plateau stress is defined as the average stress between displacements from 5 to $38 \mathrm{~mm}$. The total dissipated energy is the area under the force-displacement curves up to $38 \mathrm{~mm}$, which is described by $E_{C}$ in compression and $E_{I}$ in indentation. Tearing of the cell walls along the four edges of 
the square indenter occurred simultaneously during the indentation. Tearing energy, $E_{t}$, was calculated using the following energy conservation equation:

$$
E_{t}=E_{I}-E_{C}
$$

where, $E_{t}$ is the dissipated energy in tearing; $E_{I}$ is the energy dissipated in indentation; and $E_{C}$ is the energy dissipated in compression.

Comparisons between the FEA and experimental results in terms of plateau stress and dissipated energy are listed in Table 4. For two different types of honeycombs (H31 and H42), the simulated plateau stresses and total dissipated energies were found to be slightly lower than the corresponding experimental values in both indentation and compression. The differences were between $4.71 \%$ and $11.62 \%$, which was acceptable.

Table 4. Comparison between FEA and experimental results at $5 \mathrm{~ms}^{-1}$.

\begin{tabular}{lccccccc}
\hline & & \multicolumn{3}{c}{ Plateau Stress } & \multicolumn{3}{c}{ Dissipated Energy } \\
\cline { 3 - 8 } Test Type & Honeycombs & Exp. & FEA & Difference & Exp. & FEA & Difference \\
\cline { 3 - 8 } & & $\mathbf{M P a}$ & $\mathbf{M P a}$ & $\mathbf{\%}$ & $\mathbf{J}$ & $\mathbf{J}$ & $\%$ \\
\hline Indentation & $\mathrm{H} 31$ & 1.23 & 1.17 & 4.88 & 382 & 364 & 4.71 \\
Indentation & $\mathrm{H} 42$ & 2.13 & 1.89 & 11.26 & 644 & 571 & 11.33 \\
Compression & $\mathrm{H} 31$ & 1.06 & 0.99 & 6.66 & 314 & 294 & 6.36 \\
Compression & $\mathrm{H} 42$ & 1.64 & 1.45 & 11.58 & 499 & 441 & 11.62 \\
\hline
\end{tabular}

\section{Results and Discussion}

\subsection{The Effect of $t / l$ Ratio}

The effect of $t / l$ ratio on the mechanical properties of honeycombs is discussed in this section. Firstly, the thickness of honeycomb cell walls was fixed as $0.0254 \mathrm{~mm}$. Five different cell sizes-3.175 mm, $3.969 \mathrm{~mm}, 4.763 \mathrm{~mm}, 6.35 \mathrm{~mm}$, and $9.525 \mathrm{~mm}$-were employed. A constant strain rate of $1 \times 10^{3} \mathrm{~s}^{-1}$ was used in the simulation. The FEA results are listed in Table 5 . Both in indentation and compression, it was found that the plateau stress decreased with the increase of cell size for a constant cell wall thickness. Similar to the plateau stress, dissipated energy and tearing energy also decreased with the increase of cell size.

Table 5. FEA results of honeycombs with constant cell wall thickness and different cell sizes.

\begin{tabular}{cccccccc}
\hline $\begin{array}{c}\text { Loading } \\
\text { Type }\end{array}$ & FEA No. & $\begin{array}{c}\text { Cell Size, } \\
\mathbf{D}\end{array}$ & $\begin{array}{c}\text { Cell Wall } \\
\text { Thickness, } \mathbf{t}\end{array}$ & $\boldsymbol{t} / \boldsymbol{l}$ Ratio & $\begin{array}{c}\text { Plateau } \\
\text { Stress }\end{array}$ & $\begin{array}{c}\text { Dissipated } \\
\text { Energy }\end{array}$ & $\begin{array}{c}\text { Tearing } \\
\text { Energy }\end{array}$ \\
\cline { 2 - 7 } & $\mathbf{m m}$ & $\mathbf{m m}$ & - & $\mathbf{M P a}$ & $\mathbf{J}$ & $\mathbf{J}$ \\
\hline \multirow{5}{*}{ Indentation } & CS-I-1 & 3.175 & 0.0254 & 0.01388 & 3.74 & 1262 & 309 \\
& CS-I-2 & 3.969 & 0.0254 & 0.01109 & 2.81 & 955 & 224 \\
& CS-I-3 & 4.763 & 0.0254 & 0.00924 & 2.18 & 731 & 183 \\
& CS-I-4 & 6.35 & 0.0254 & 0.00692 & 1.39 & 472 & 153 \\
& CS-I-5 & 9.525 & 0.0254 & 0.00462 & 0.73 & 256 & 78 \\
\hline Compression & CS-C-3 & 4.763 & 0.0254 & 0.00924 & 1.69 & 548 & - \\
& CS-C-4 & 6.35 & 0.0254 & 0.00692 & 0.99 & 319 & - \\
& CS-C-2 & 3.175 & 0.0254 & 0.01388 & 2.95 & 953 & - \\
& CS-C-5 & 9.525 & 0.0254 & 0.00462 & 0.55 & 178 & - \\
\hline
\end{tabular}

Secondly, honeycomb cell size, $D$, was kept constant at $4.763 \mathrm{~mm}$ (the corresponding cell edge length was $2.75 \mathrm{~mm}$ ). The thickness of the cell wall varied from 0.0178 to $0.1524 \mathrm{~mm}$, where the 
corresponding $t / /$ ratios were from 0.00647 to 0.05542 . The simulation results at a constant strain rate of $1 \times 10^{3} \mathrm{~s}^{-1}$ are listed in Table 6 .

Table 6. FEA results of honeycombs with constant cell size and different cell wall thicknesses.

\begin{tabular}{ccccccc}
\hline $\begin{array}{c}\text { Loading } \\
\text { Type }\end{array}$ & FEA No. & $\begin{array}{c}\text { Cell Wall } \\
\text { Thickness, } \mathbf{t}\end{array}$ & $\boldsymbol{t}$ /l Ratio & $\begin{array}{c}\text { Plateau } \\
\text { Stress }\end{array}$ & $\begin{array}{c}\text { Dissipated } \\
\text { Energy }\end{array}$ & $\begin{array}{c}\text { Tearing } \\
\text { Energy }\end{array}$ \\
\cline { 2 - 6 } & & $\mathbf{m m}$ & - & $\mathbf{M P a}$ & $\mathbf{J}$ & $\mathbf{J}$ \\
\hline \multirow{5}{*}{ Indentation } & TL-I-1 & 0.0178 & 0.00647 & 1.05 & 378 & 91 \\
& TL-I-2 & 0.0254 & 0.00924 & 2.16 & 727 & 187 \\
& TL-I-3 & 0.0381 & 0.01386 & 3.72 & 1260 & 315 \\
& TL-I-4 & 0.0508 & 0.01847 & 4.91 & 1642 & 387 \\
& TL-I-5 & 0.0635 & 0.02309 & 5.98 & 2005 & 449 \\
& TL-I-6 & 0.0762 & 0.02771 & 7.24 & 2415 & 526 \\
& TL-I-7 & 0.0889 & 0.03233 & 8.09 & 2695 & 678 \\
& TL-I-8 & 0.1016 & 0.03695 & 9.21 & 3082 & 829 \\
& TL-I-9 & 0.127 & 0.04618 & 11.39 & 3823 & 1064 \\
& TL-I-10 & 0.1524 & 0.05542 & 13.24 & 4451 & 1370 \\
\hline \multirow{5}{*}{ Compression } & TL-C-1 & 0.0178 & 0.00647 & 0.89 & 287 & - \\
& TL-C-2 & 0.0254 & 0.00924 & 1.66 & 540 & - \\
& TL-C-3 & 0.0381 & 0.01386 & 2.93 & 945 & - \\
& TL-C-4 & 0.0508 & 0.01847 & 3.91 & 1255 & - \\
& TL-C-5 & 0.0635 & 0.02309 & 4.82 & 1556 & - \\
& TL-C-6 & 0.0762 & 0.02771 & 6.24 & 1889 & - \\
& TL-C-7 & 0.0889 & 0.03233 & 6.65 & 2017 & - \\
& TL-C-8 & 0.1016 & 0.03695 & 7.34 & 2253 & - \\
& TL-C-9 & 0.127 & 0.04618 & 8.86 & 2759 & - \\
& TL-C-10 & 0.1524 & 0.05542 & 9.86 & 3081 & - \\
\hline
\end{tabular}

The plateau stresses of honeycombs subjected to out-of-plane compression and indentation were found to increase with $t / l$ ratio (Figure 5) by power laws. The exponents are 1.47 for compression (Equation (2a)) and 1.36 for indentation (Equation (2b)). Xu et al. [6,19] also found a similar power law relation between plateau stress and $t / l$ ratio with an exponent of 1.49 .

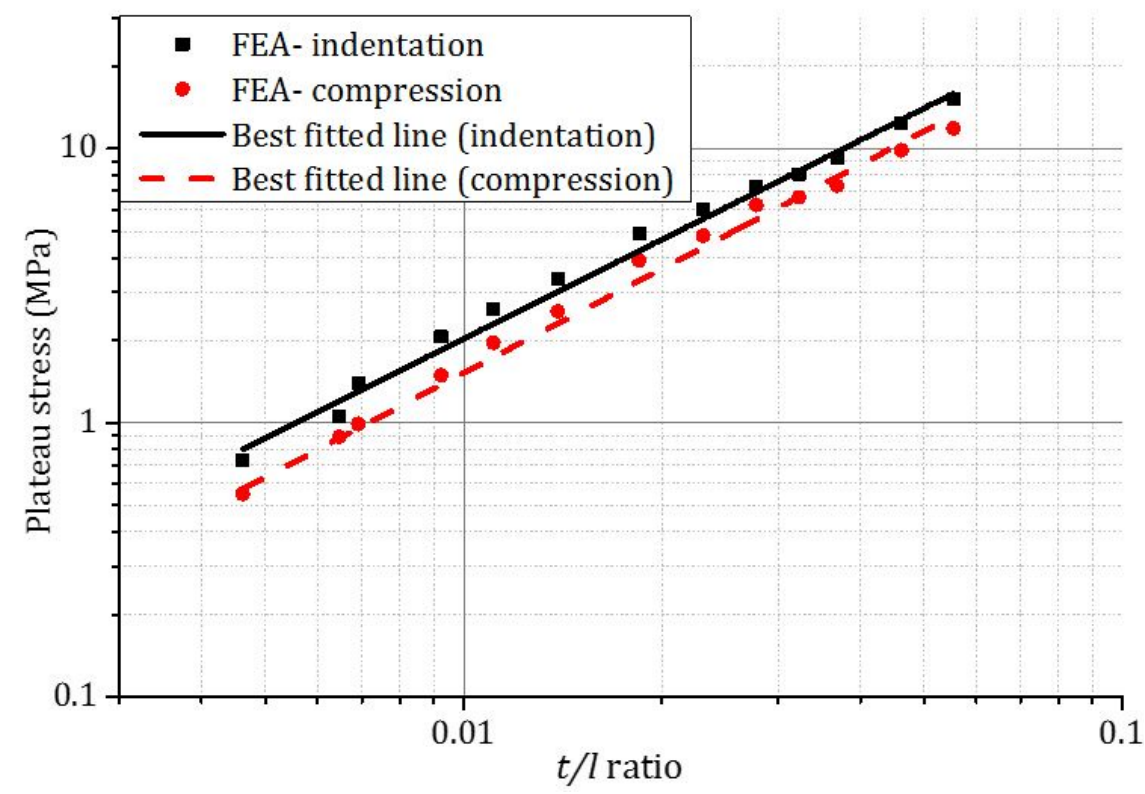

Figure 5. The effect of $t / l$ ratio on the plateau stresses of honeycombs under compression and indentation loads at a strain rate of $1 \times 10^{3} \mathrm{~s}^{-1}$. 
For compression,

$$
\sigma_{p l}=2.93 \sigma_{y s}(t / l)^{1.47}
$$

For indentation,

$$
\sigma_{p l}=4.49 \sigma_{y s}(t / l)^{1.36}
$$

The tearing energies were calculated using Equation (1) and are shown in Tables 5 and 6. Tearing energy was also found to increase with the $t / l$ ratio. The fracture area, $A_{t}$, was calculated as the product of the circumferential length of the square shape indenter $(90 \mathrm{~mm} \times 4)$ and the displacement $(38 \mathrm{~mm})$ of the indenter [3]. The relationship between the tearing energy per fracture area, $A_{t}$, and the relative density, $\rho / \rho_{0}$, is shown in Figure 6. It was found that with the increase of $t / l$ ratio or relative density, the tearing energy per unit fracture area increased.

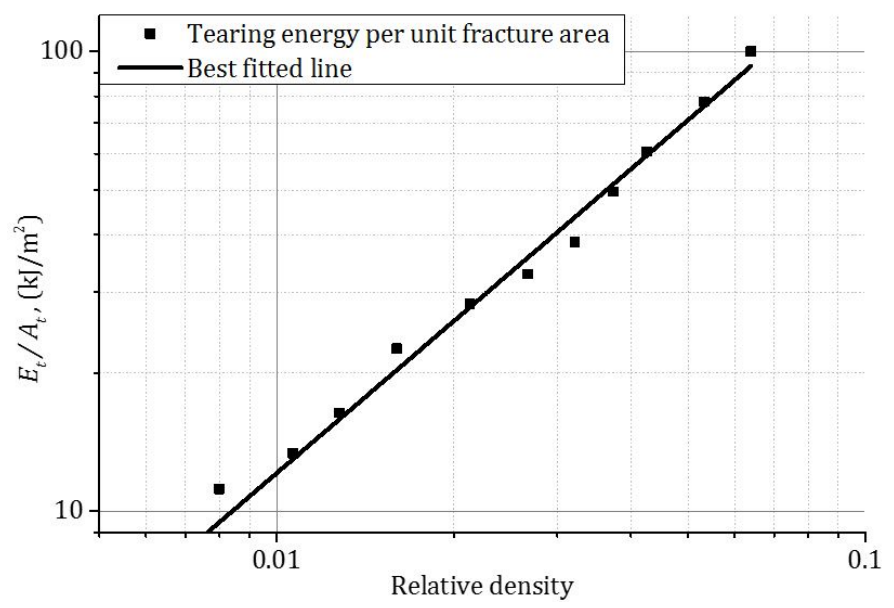

Figure 6. The relationship between the tearing energy per unit fracture area and relative density of honeycomb at a strain rate of $1 \times 10^{3} \mathrm{~s}^{-1}$.

Previously, Zhou and Mayer [3] and Ashab et al. [7] conducted quasi-static indentation tests on different honeycombs. Moreover, other researchers [22-24] conducted quasi-static indentation tests on aluminum foams. Shi et al. [22] proposed a theoretical formula and an empirical formula between tearing energy per unit fracture area and relative density. In order to compare these two types of cellular materials (honeycomb and foam, which are made from different aluminum alloys), tearing energy per unit fracture area was normalized by the yield stress of the parent aluminum alloy for both honeycombs and foams. The relationship between the normalized tearing energy per unit fracture area and relative density is shown in Figure 7. Using yield stress $\sigma_{y s}=150 \mathrm{MPa}$ for the foams in Shi et al. [22], Olurin et al. [23], and Olurin et al. [24], the equation proposed by Shi et al. [22], $\gamma=119.4 \bar{\rho}$, can be rewritten as $\gamma=0.79 \sigma_{y s} \bar{\rho}$, where $\gamma, \sigma_{y s}$, and $\bar{\rho}$ are tearing energy per unit area, yield stress of aluminum, and relative density of foam, respectively. The normalized tearing energy per unit fracture area for both aluminum foams and honeycombs are plotted together in terms of relative density in Figure 7. The equation of the best fitted line is as follows, which is very similar to that for foams:

$$
\frac{E_{t}}{A_{t}}=0.80 \sigma_{y s}\left(\rho / \rho_{0}\right)
$$




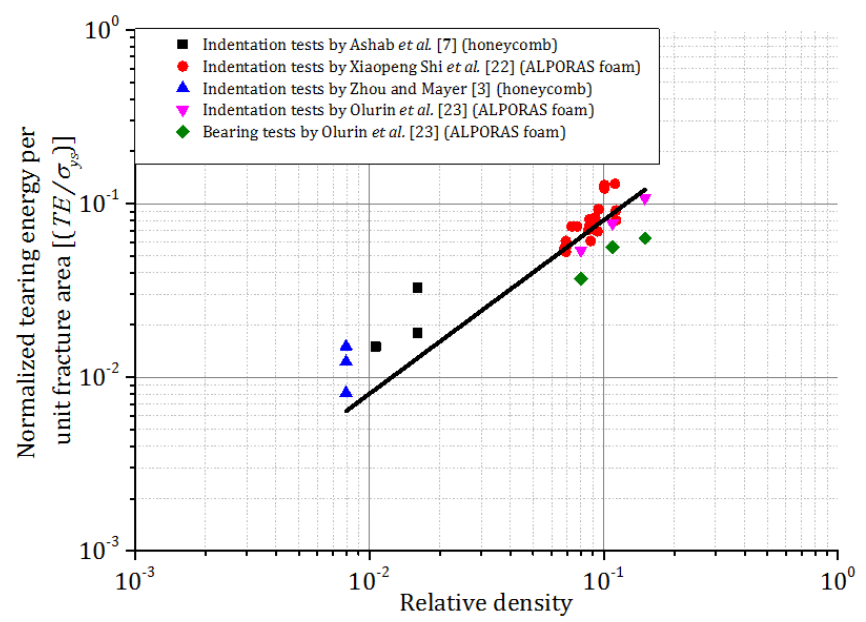

Figure 7. Normalized tearing energy per unit fracture area vs. relative density of different cellular materials.

\subsection{The Effect of Strain Rate, $\dot{\varepsilon}$}

\subsubsection{Plateau Stress}

In the previous experimental study [7], honeycombs were crushed at low and intermediate strain rates $\left(1 \times 10^{-3}\right.$ to $\left.1 \times 10^{2} \mathrm{~s}^{-1}\right)$. FEA was conducted on honeycombs at high strain rates $\left(1 \times 10^{2}\right.$ to $\left.1 \times 10^{4} \mathrm{~s}^{-1}\right)$. Both experimental and FEA results are shown in Figure 8, which demonstrates the influence of strain rate on the plateau stress of two different honeycombs subjected to out-of-plane indentation and compression loadings, respectively. For both types of honeycombs, the plateau stress increased with strain rate in both indentation and compression. Due to the higher $t / l$ ratio, the plateau stress is larger for honeycomb $\mathrm{H} 42$ than that for honeycomb H31.

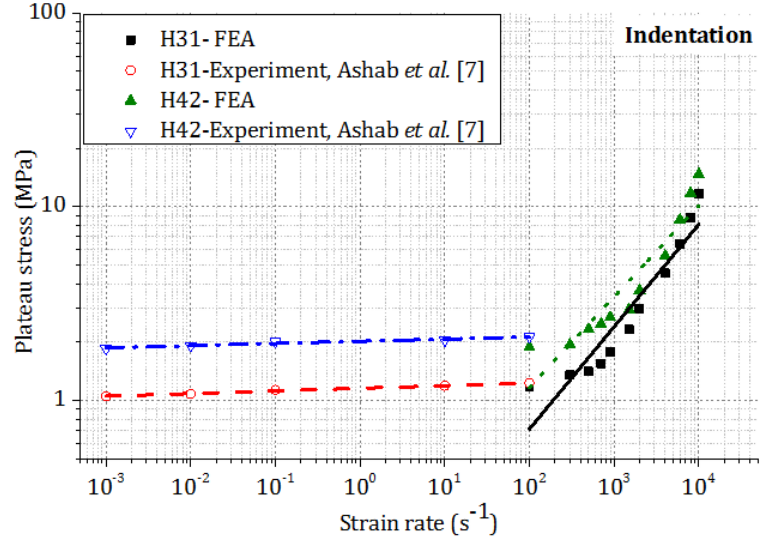

(a)

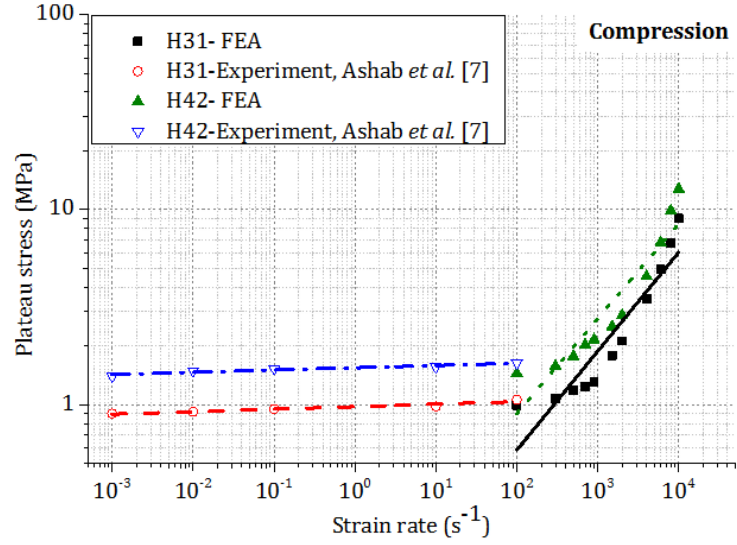

(b)

Figure 8. Effect of strain rate on the plateau stresses of two types of honeycombs subjected to: (a) indentation; (b) compression.

Experiments and FEA of compression of aluminum honeycombs were conducted by various researchers [7,15,25-30]. In previous experimental study [7], enhancement in the plateau stress was observed at low and intermediate loading velocities. Wang et al. [26] reported remarkable enhancement of plateau stress at high impact velocity $\left(20-80 \mathrm{~ms}^{-1}\right)$. Goldsmith and Sackman [27] found a 50\% enhancement in plateau stress at dynamic velocities up to $35 \mathrm{~ms}^{-1}$. Zhao and Gary [28] observed significant enhancement (approximately $40 \%$ ) in the plateau stress when the loading velocity increased 
from quasi-static to dynamic $\left(2-28 \mathrm{~ms}^{-1}\right)$. Similar enhancement of plateau stress with the loading velocity was also discussed by Hou et al. [29] and Zhao et al. [30]. In order to compare these results with the current FEA, plateau stresses of honeycombs were normalized as $\left(\sigma_{p l} / \sigma_{y s}\right) /(t / l)^{1.5}$ and plotted in Figure 9 in terms of strain rate. These current FEA results show significant enhancement of plateau stress at high impact velocities, which agree very well with the FEA results of Deqiang et al. [15].

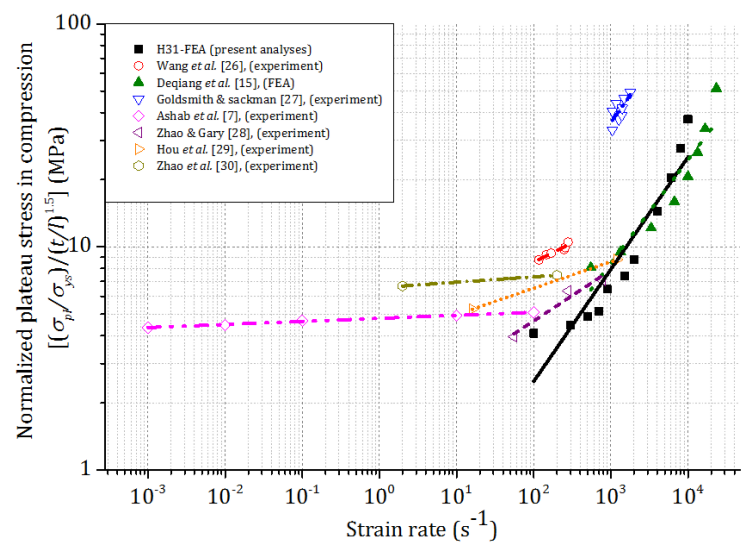

Figure 9. Normalized plateau stress of honeycomb vs. strain rate of honeycombs in compression.

\subsubsection{Energy Dissipation}

Figure 10 shows the effect of strain rate on the dissipated energy of two types of honeycombs under indentation and compression loadings, respectively. Similar to the plateau stress, for two types of honeycombs the dissipated energy increased with strain rate in both indentation and compression. For honeycomb H42, the dissipated energies in both indentation and compression were found to be larger than those of honeycomb $\mathrm{H} 31$ due to the higher $t / l$ ratio.

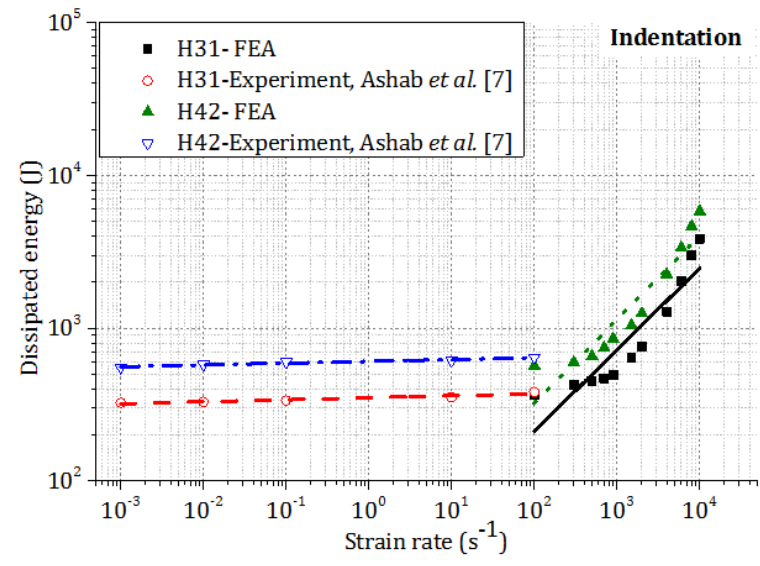

(a)

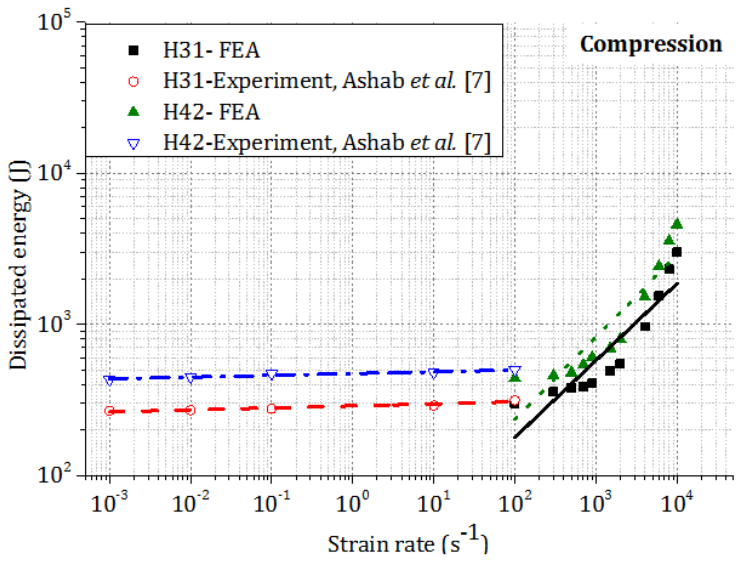

(b)

Figure 10. Effect of high strain rate on the total dissipated energy of two types of honeycombs: (a) indentation; (b) compression.

Tearing energy, which is the difference between the total energies dissipated in indentation and compression, was plotted in Figure 11. Due to the higher $t / l$ ratio, the magnitude of tearing energy is larger for honeycomb H42 than that for honeycomb H31 at the same strain rate. For both honeycombs, tearing energy increases with strain rate. The fitted curve for tearing energy per unit fracture area for honeycombs at different strain rates is shown in Figure 12. 


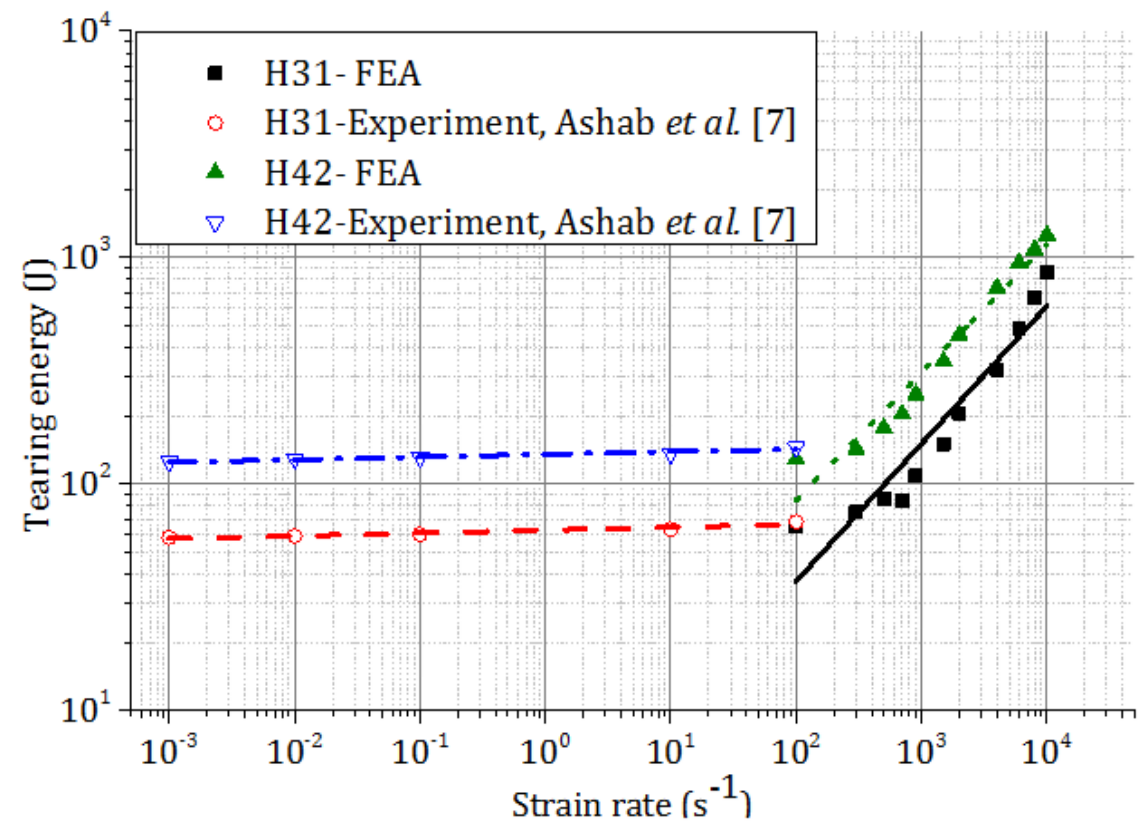

Figure 11. Effect of strain rate on the tearing energy of different honeycombs.

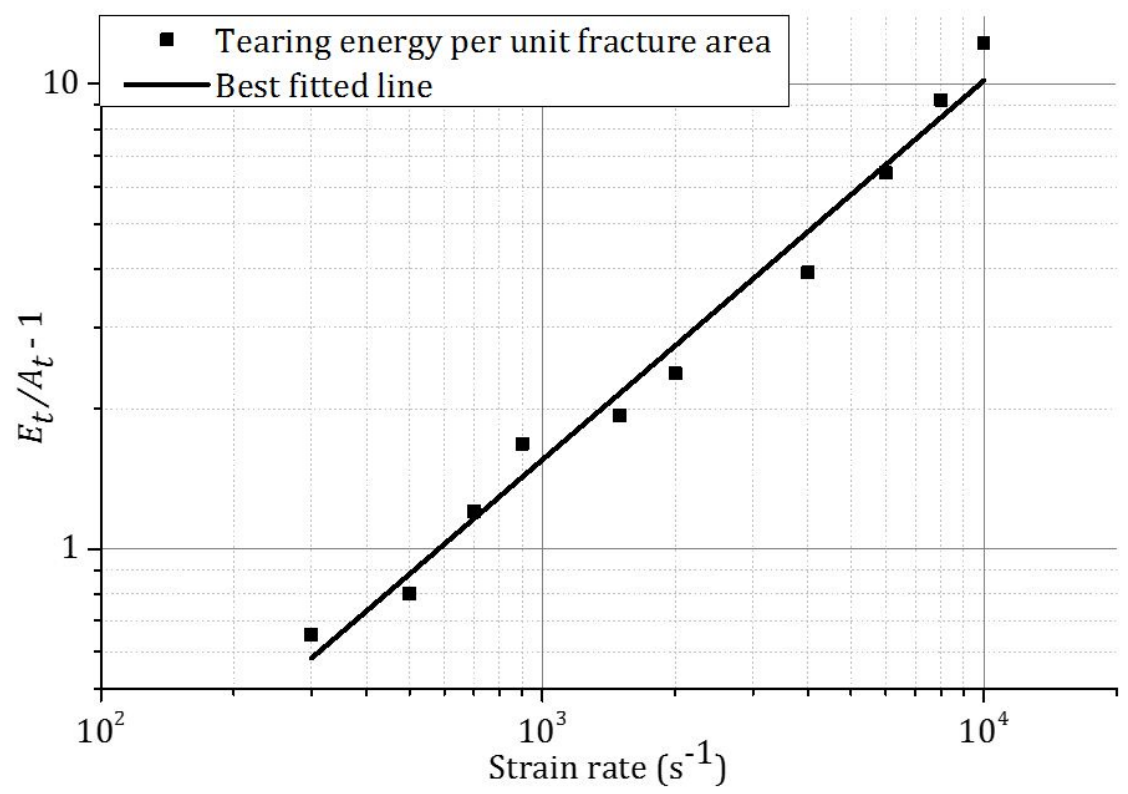

Figure 12. The dependency of tearing energy per unit fracture area of honeycombs and strain rate.

The relation between the tearing energy per unit fracture area and the relative density and strain rate is described by the following equation:

$$
\frac{E_{t}}{A_{t}}=1.37 \times 10^{3}\left(\rho / \rho_{0}\right)^{1.32}\left(1+8.77 \times 10^{-4} \dot{\varepsilon}^{1.03}\right)
$$

\subsection{Deformation Pattern of Aluminum Honeycombs Subjected to Compression and Indentation}

Figure 13 shows the enlarged isometric and front (sectional plane) views of honeycombs H31 under out-of-plane indentation and compression loads. Three images of deformation were taken at a displacement of $0 \mathrm{~mm}, 20 \mathrm{~mm}$, and $40 \mathrm{~mm}$, respectively, from the animation of FEA by using LS-Prepost 
software [31]. In Figure 13a it is seen that the progressive buckling of the cell wall occurs from both ends of the honeycomb simultaneously and propagates to the middle region of the honeycomb, which is similar to that observed in the previous experimental study [7]. Deformation mode is found to be independent of strain rate. Xu et al. [6] also observed a negligible effect of strain rate on the buckling of honeycomb cells in the out-of-plane compression.
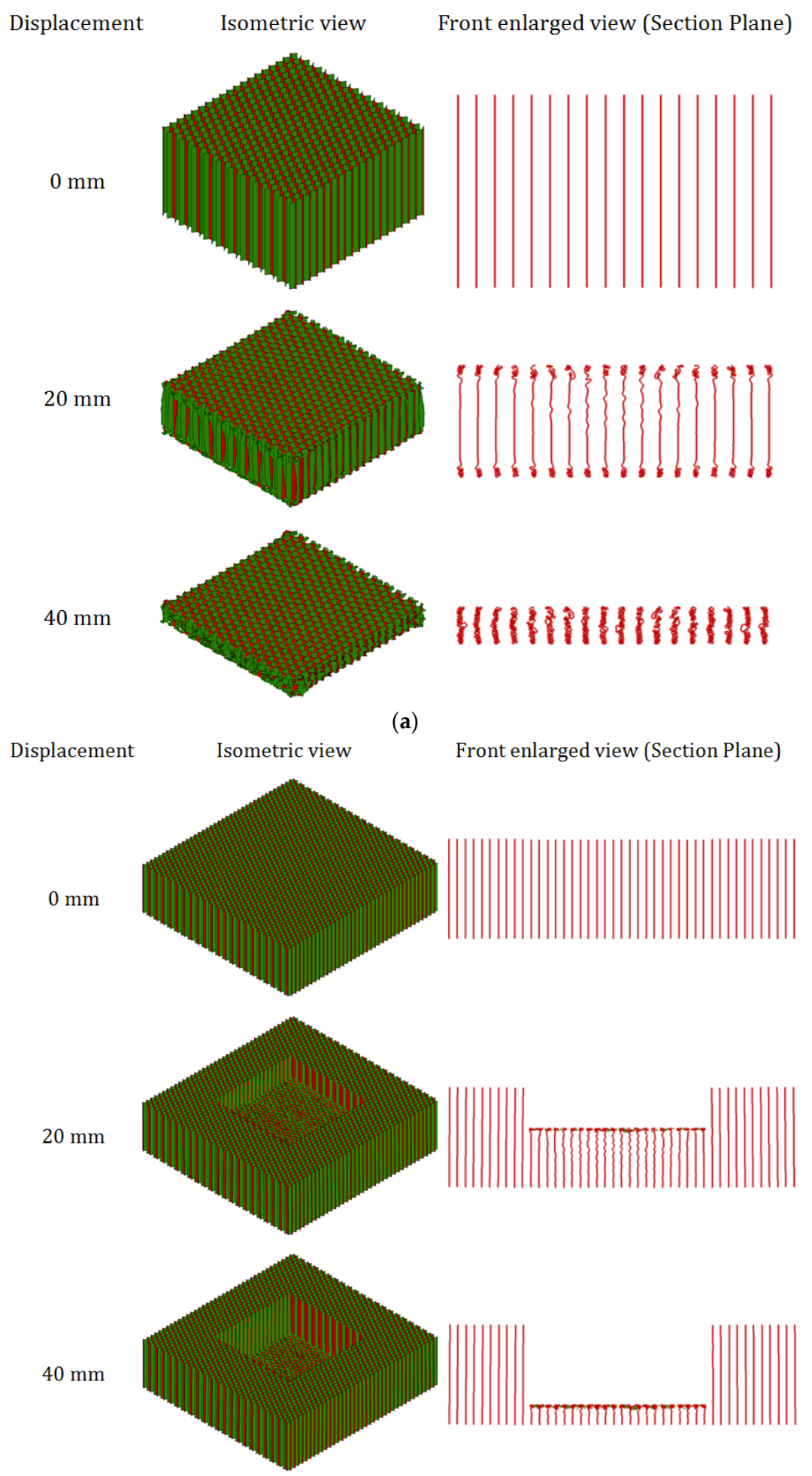

(b)

Figure 13. Deformation of honeycomb H31 at $5 \mathrm{~ms}^{-1}$ : (a) compression; (b) indentation. 
In the previous experimental study, it was impossible to observe the deformation of honeycomb under the indenter. In the current FEA, the deformation of honeycomb in indentation is observed from the front sectional plane view, as shown in Figure 13b. It is found that the progressive buckling of cell walls initiates from the top end of the honeycomb, which is immediately beneath the indenter, and propagates in the same manner till densification. Progressive buckling takes place in the middle portion of the honeycomb model underneath the indenter, which is associated with the tearing of cell walls along the four edges of the indenter. No significant difference is observed in the buckling pattern at different strain rates.

\section{Conclusions}

In this finite element analysis, different honeycomb models have been developed by using ANSYS/LS-DYNA to study the mechanical behavior of honeycombs under out-of-plane indentation and compression loads over a wide range of high strain rates from $1 \times 10^{2}$ to $1 \times 10^{4} \mathrm{~s}^{-1}$. The FE models have been validated by the previous experimental results (compression and indentation) in terms of deformation, stress-strain curves, plateau stress, and dissipated energy. A reasonable agreement between the FEA and experimental results has been found for both honeycombs H31 and $\mathrm{H} 42$.

It is found that the plateau stress, dissipated energy, and tearing energy increase with the $t / l$ ratio. For a constant strain rate of $1 \times 10^{3} \mathrm{~s}^{-1}$, the plateau stresses increase with $t / l$ ratio by power laws with exponents of 1.47 and 1.36 for compression and indentation, respectively.

Moreover, the plateau stress, dissipated energy, and tearing energy increase gradually for low and intermediate strain rates. Significant enhancement in the plateau stress, dissipated energy, and tearing energy is observed at high strain rates for honeycombs subjected to either compression or indentation loads. An empirical formula is proposed for the tearing energy per unit fracture area in terms of strain rate and relative density of honeycombs.

The current FEA reveals that at velocities at $5 \mathrm{~ms}^{-1}$, under indentation, plastic buckling of the honeycomb cell walls occurs from the end that is adjacent to the indenter, while under compression the buckling of honeycomb cell walls occurs from both ends of the honeycomb.

It is found that under quasi-static indentation, the empirical formula proposed by Shi et al. for foam can be used for honeycombs as well.

Acknowledgments: A.S.M. Ayman Ashab is grateful for the financial support provided by Swinburne University of Technology, Victoria, Australia through a postgraduate research scholarship. The authors are thankful to Shanqing Xu for his help and Leap Australia for the technical support of ANSYS/LS-DYNA.

Author Contributions: Dong Ruan and Guoxing Lu proposed the finite element models; A.S.M. Ayman Ashab and Arafat A. Bhuiyan conducted finite element analysis; A.S.M. Ayman Ashab, Dong Ruan, Guoxing Lu and Arafat A. Bhuiyan analyzed and interpreted the data; A.S.M. Ayman Ashab drafted the paper; Dong Ruan and Guoxing Lu revised the paper.

Conflicts of Interest: The authors declare no conflict of interest.

\section{References}

1. Versatile Flooring Panel Suitable for Passenger Cargo Compartment. The Grill Corporation. Available online: http://www.thegillcorp.com/public/mcg_msds/datasheets/Gillfloor_5424_Panel.pdf (accessed on 28 February 2015).

2. koenigsegg. Agera, Specification, Chassis, Optimal Weight Distribution and Safety Chassis. Available online: http:/ /www.Koenigsegg.Com/models/agera/ (accessed on 18 September 2014).

3. Zhou, Q.; Mayer, R.R. Characterization of aluminum honeycomb material failure in large deformation compression, shear, and tearing. J. Eng. Mater. Technol. 2002, 124, 412-420. [CrossRef]

4. Wu, E.; Jiang, W.S. Axial crush of metallic honeycombs. Int. J. Impact Eng. 1997, 19, 439-456. [CrossRef] 
5. Baker, W.E.; Togami, T.C.; Weydert, J.C. Static and dynamic properties of high-density metal honeycombs. Int. J. Impact Eng. 1998, 21, 149-163. [CrossRef]

6. Xu, S.; Beynon, J.H.; Ruan, D.; Lu, G. Experimental study of the out-of-plane dynamic compression of hexagonal honeycombs. Compos. Struct. 2012, 94, 2326-2336. [CrossRef]

7. Ashab, A.; Ruan, D.; Lu, G.; Xu, S.; Wen, C. Experimental investigation of the mechanical behavior of aluminum honeycombs under quasi-static and dynamic indentation. Mater. Des. 2015, 74, 138-149. [CrossRef]

8. Vijayasimha Reddy, B.G.; Sharma, K.V.; Yella Reddy, T. Deformation and impact energy absorption of cellular sandwich panels. Mater. Des. 2014, 61, 217-227. [CrossRef]

9. Alavi Nia, A.; Sadeghi, M.Z. An experimental investigation on the effect of strain rate on the behaviour of bare and foam-filled aluminium honeycombs. Mater. Des. 2013, 52, 748-756. [CrossRef]

10. Mozafari, H.; Khatami, S.; Molatefi, H. Out of plane crushing and local stiffness determination of proposed foam filled sandwich panel for korean tilting train express-Numerical study. Mater. Des. 2015, 66, 400-411. [CrossRef]

11. Guo, X.E.; Gibson, L.J. Behavior of intact and damaged honeycombs: A finite element study. Int. J. Mech. Sci. 1999, 41, 85-105. [CrossRef]

12. Ruan, D.; Lu, G.; Wang, B.; Yu, T.X. In-plane dynamic crushing of honeycombs-A finite element study. Int. J. Impact Eng. 2003, 28, 161-182. [CrossRef]

13. Hu, L.; You, F.; Yu, T. Analyses on the dynamic strength of honeycombs under the y-directional crushing. Mater. Des. 2014, 53, 293-301. [CrossRef]

14. Hu, L.; You, F.; Yu, T. Effect of cell-wall angle on the in-plane crushing behaviour of hexagonal honeycombs. Mater. Des. 2013, 46, 511-523. [CrossRef]

15. Deqiang, S.; Weihong, Z.; Yanbin, W. Mean out-of-plane dynamic plateau stresses of hexagonal honeycomb cores under impact loadings. Compos. Struct. 2010, 92, 2609-2621. [CrossRef]

16. ANSYS 15-Mechanical User's Guide; Version No 15; ANSYS, Inc.: Canonsburg, PA, USA, 2013.

17. Yamashita, M.; Gotoh, M. Impact behavior of honeycomb structures with various cell specifications-Numerical simulation and experiment. Int. J. Impact Eng. 2005, 32, 618-630. [CrossRef]

18. Wierzbicki, T. Crushing analysis of metal honeycombs. Int. J. Impact Eng. 1983, 1, 157-174. [CrossRef]

19. Xu, S.; Ruan, D.; Beynon, J.H. Finite element analysis of the dynamic behavior of aluminum honeycombs. Int. J. Comput. Methods 2014, 11. [CrossRef]

20. HexWeb. Available online: http://www.hexcel.com/products/industries/ihoneycomb (accessed on 30 June 2015).

21. Ju, J.; Summers, J.D.; Ziegert, J.; Fadel, G. Design of honeycomb meta-materials for high shear flexure. Proc. ASME Des. Eng. Tech. Conf. 2009, 5, 805-813.

22. Shi, X.; Li, Y.; Lu, G.; Shen, C. A testing method for tearing energy of aluminum foams. Mater. Sci. Eng. A 2014, 614, 284-290. [CrossRef]

23. Olurin, O.B.; Fleck, N.A.; Ashby, M.F. Indentation resistance of an aluminium foam. Scripta Mater. 2000, 43, 983-989. [CrossRef]

24. Olurin, O.B.; Fleck, N.A.; Ashby, M.F. Deformation and fracture of aluminium foams. Mater. Sci. Eng. A 2000, 291, 136-146. [CrossRef]

25. Zhao, H.; Abdennadher, S. On the strength enhancement under impact loading of square tubes made from rate insensitive metals. Int. J. Solids Struct. 2004, 41, 6677-6697. [CrossRef]

26. Wang, Z.; Tian, H.; Lu, Z.; Zhou, W. High-speed axial impact of aluminum honeycomb-Experiments and simulations. Compos. Part B Eng. 2014, 56, 1-8. [CrossRef]

27. Goldsmith, W.; Sackman, J.L. An experimental study of energy absorption in impact on sandwich plates. Int. J. Impact Eng. 1992, 12, 241-262. [CrossRef]

28. Zhao, H.; Gary, G. Crushing behaviour of aluminium honeycombs under impact loading. Int. J. Impact Eng. 1998, 21, 827-836. [CrossRef]

29. Hou, B.; Zhao, H.; Li, Y. Impact enhancement of the out-of-plane behaviour of honeycombs. Mater. Res. Innovations 2011, 15, s209-s212. [CrossRef] 
30. Zhao, H.; Elnasri, I.; Abdennadher, S. An experimental study on the behaviour under impact loading of metallic cellular materials. Int. J. Mech. Sci. 2005, 47, 757-774. [CrossRef]

31. Ls-Prepost. Available online: http://www.Lstc.Com/download (accessed on 30 June 2013).

(c) 2016 by the authors; licensee MDPI, Basel, Switzerland. This article is an open access article distributed under the terms and conditions of the Creative Commons by Attribution (CC-BY) license (http://creativecommons.org/licenses/by/4.0/). 